\title{
Um contributo da Teoria da Comunicação para a Teoria dos Imaginários Sociais
}

\author{
Samuel Mateus
}

\section{Introdução}

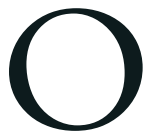

conceito de "Imaginário Social" oferece-nos hoje um inestimável recurso para avaliar a imanência significante das sociedades contemporâneas. Com efeito, podemos considerá-lo um marco interpretativo da realidade social (Saez e Pasin, 2016: 127) e uma noção operativa que nos permite identificar e reconhecer as transformações incessantes dos esquemas de significado.

À medida que novas abordagens do imaginário social vão sendo realizadas (cf. Pintos, 2005) e novas metodologias qualitativas surgem (cf. Dittus, 2006), o imaginário social vai sendo revestido de uma importância ímpar no desenvolvimento dos processos sociais. Enquanto criação incessante e indeterminada de figuras e imagens, o imaginário é instituição de um magma de significações sociais (Castoriadis, 1989: 12). Dito de outro modo, as relações histórico-sociais e as interações humanas dependem, numa parte significativa, das construções mentais com que as sociedades operam, avaliam e agem. A ideação coletiva e o pensar coletivo social encontram-se, assim, em estreita articulação com as macro-estruturas - instituintes e instituídas imaginantes cujo poder simbólico as coloca como fundamentais intervenientes nas organizações sociais. Dito por outras palavras, os imaginários sociais consignam-se, precisamente, por serem formas de significação institucionalizadas que as sociedades adotam com vista a operar processos de decisão, ação e juízo. Pensar os imaginários sociais equivale a ponderar a dinâmica generativa das figurações sociais que tornam as ações, hábitos e sistemas de pensamento inteligíveis. No fundo, os imaginários 
sociais retrabalham o sentido através da partilha de uma forma comum de perspectivar e compreender as atividades humanas. Daí que o imaginário do luxo, por exemplo, operacionalize um magma de significações ligadas à liberdade individual, à singularidade, ao hedonismo, ao ócio, consumo conspícuo ou estatuto socioeconômico.

Podemos definir o imaginário social como o conjunto de valores, instituições, regras normativas, símbolos, imagens e mitos comuns a um determinado grupo social e que coloca em tensão ambivalente razão e emoção, realidade e imaginação, desejo e ordem, simbólico e não-simbólico. Alude não apenas às ideologias e estereótipos como também aos afetos coletivos sejam eles visuais (fotografia, pintura, imagens 3D etc.) ou linguísticos (metáfora, símbolo, mito etc.). Estamos, assim, no domínio das representações complexas - ou disposições representativas - que estruturam as interações ao providenciar uma base cognitiva (Wunenburger, 2008). Note-se que aludir ao imaginário social não é referenciar exatamente as representações coletivas de que Durkheim (2001) dissertava. A natureza do conceito de "imaginário social" é menos epidérmica sendo mais elementar e fundadora das coletividades. Tem mais a ver com as derradeiras articulações de sentido que dotariam de inteligibilidade a praxis social (Pasin, 2011: 101), e com um centro simbólico a partir do qual a coesão comunitária irradia. Também não diz exatamente respeito a uma consciência coletiva (Pintos, 2000), mas uma intrincada trama de figurações que permeiam as sociedades.

De fato, as estruturas representativas que compõem o imaginário apresentam-se enquanto operadores compreensivos (Sola-Morales, 2014: 7) que expressam afetos, ideias, valores e normas que orientam as sociedades, e que permitem ao indivíduo definir uma concepção de si próprio e dos outros do ponto de vista coletivo. Eles possuem uma função epistemológica de dar a compreender o mundo através de uma pluralidade de sentidos potencialmente ambíguos. Contudo, são estas diferentes e ambivalentes figurações multimodais e discursivas que estabelecem uma relação autopoiética das sociedades. Na verdade, os imaginários são condição de todo o pensamento ${ }^{1}$ (Castoriadis, 1998) e concorrem para produzir uma continuidade e estabilidade (Pintos, 2005) no seio dos múltiplos e variados repertórios imaginantes.

Os imaginários são, desse modo, cruciais na ordenação e compreensão do mundo. Como salienta Cabrera (2004: 3), os imaginários configuram as significações sociais que mostram, contrastam e (possivelmente) ocultam uma realidade social. "Os imaginários sociais possuem uma função primária que se podia definir como a elaboração e distribuição generalizada de instrumentos de perceção da realidade social construída como realmente existente" (Pintos, 1995: 11).

Baeza (2000) compreende, desse modo, os imaginários sociais como um patrimônio representativo: um conjunto de imagens mentais acumuladas pelo indivíduo durante o processo de socialização. Não se trata, como assinala Castoriadis (1989), do imaginário social representar um qualquer objeto, entidade ou pessoa mas sim da (re)criação psíquica, social e histórica de figuras simbólicas (imagéticas e

104 ALCEU - v.18 - n.36 - p. 103 a I2I - jan-jun./20I8 
não-imagéticas) que determinam significativamente o pensamento coletivo. É nessa medida que Baczko (1991) sublinha o aspecto regulador da vida coletiva que os imaginários contêm e a sua ligação ao poder nas sociedades. "O impacto dos imaginários sociais nas mentalidades depende largamente da sua difusão, dos circuitos e dos meios de que dispõe. Para atingir a dominação simbólica, é fundamental controlar esses meios que são igualmente instrumentos de persuasão, pressão e inculcação de valores e crenças" (Baczko, 1991: 31).

Que os imaginários sociais detêm uma capacidade de intervir e unificar as estruturas sociais através de um poderoso universo simbólico parece indiscutível. Ao canalizar e instituir as estruturas significantes do próprio quotidiano, os imaginários encontram-se muito associados aos projetos coletivos de uma sociedade. $\mathrm{Na}$ maioria das discussões empreendidas salienta-se o imaginário social como condição de possibilidade dos esquemas organizadores do pensamento - individual e coletivo. Porém, raramente se explora o modo como o imaginário se institui coletivamente, nem se explica o modo de adoção desses esquemas organizadores do pensamento a que chamamos de disposições representativas.

Certo, o imaginário é pensamento. Todavia, não é puro pensamento, mas sim pensamento de uma coletividade. A maioria dos trabalhos sobre o imaginário social não preocupa com esta passagem desde a criação das disposições representativas (a um nível individual) para a adoção dessas mesmas disposições (a um nível coletivo).

Precisamos, então, de refletir sobre esta dupla articulação "individual-coletivo" ou "singular-plural" e para tal é fundamental dar conta do papel da publicidade (ou principio de publicidade no sentido Kanteano de Publizität) na configuração dos imaginários sociais. Se os imaginários são condição de possibilidade das sociedades, a publicidade deve ser considerada como condição de possibilidade dos imaginários sociais. Com efeito, sem a ação propagadora, disseminadora e coletiva da publicidade, os imaginários sociais poderiam ser instituídos, mas não poderiam ser instituintes. Apenas porque eles são passíveis de apropriação e de reconstrução publicitárias é que os imaginários sociais atingem a sua máxima concretização.

Visto que a natureza dos imaginários é propriamente imaterial e ideacional, eles requerem formas materiais que os tornem visíveis - e reconhecíveis. Daí que o domínio simbólico seja central e expresse a força atuante do imaginário. Temos de contemplar a dimensão publicitária (ou pública) do universo simbólico uma vez que cabe à publicidade dar a ver, dar a agir e dar a pensar o universo simbólico de que se reveste a materialidade dos imaginários sociais. Entre o real e o ideal, o material e o imaterial deparamo-nos com o "transcendente comunitário" (Castoriadis, 1989: 254) cuja presentificação, acrescentaríamos, é sempre mediada pelo princípio de publicidade, um princípio arquetípico presente em todas as sociedades (Mateus, 2012a).

A publicidade fluidifica as práticas coletivas que integram e trabalham os imaginários sociais. Sem um princípio agregador, comunitário e comunicacional que 
a publicidade encarna, a teoria dos imaginários sociais carece de um instrumento concetual que nos permita extrapolar a mera criação imaginária para uma partilha comum do sentido oferecido por determinado imaginário social. A publicidade opera, assim, a transposição do individual ao coletivo e vice-versa. Ela funciona como o principal centro simbólico das sociedades. É precisamente este aspeto que a liga, de forma indelével, à noção de "Imaginário Social".

O presente artigo oferece uma visão comunicacional dos imaginários sociais ao salientar o papel da publicidade na sua figuração e re-figuração. Ele revê a perspetiva em que se procura identificar as vantagens que a teoria dos imaginários sociais acrescenta à teoria da comunicação (Dittus, 2006). Isto é, pretende-se inverter a orientação habitual de reflexão, e sublinhar como a ação imaginante é uma ação de ordem comunicacional. Isto é, a teoria da comunicação é um campo de extrema proficuidade para dar conta dos imaginários sociais.

Nesta reflexão, propomos a comunicação e a publicidade como categorias-chave para compreender a noção de "imaginário social". Não tanto a comunicação como uma forma de interação determinada imaginariamente mas sim os imaginários sociais como formas simbólicas dinâmicas e interativas determinadas comunicacional e publicamente.

Assim, começaremos por esquissar duas abordagens da comunicação no estudo dos imaginários para em seguida esclarecermos de que modo a Teoria da Comunicação pode beneficiar o estudo dos imaginários sociais. Por fim, dissertarmos sobre a importância da publicidade e propormos a ideia de um "Imaginal Público".

\section{Comunicação: objeto ou ângulo de análise}

O primeiro passo para compreendermos a relação entre Imaginário e Comunicação é distinguir aquilo que Barros (2013: 16) apelida de "bi-frontismo do imaginário", isto é, o imaginário enquanto tema para uma abordagem comunicacional ou o imaginário enquanto perspectiva heurística na exploração de um objeto comunicativo.

Assim, o investigador neste domínio é confrontado como duas opções principais: um, inquirir o imaginário de modo aplicado a um objeto de estudo associado à comunicação ou a um meio de comunicação, como por exemplo, o imaginário jornalístico, o imaginário da televisão, o imaginário do cinema etc.; dois, inquirir o imaginário enquanto conceito articulado com a comunicação procurando reconhecer de que modo o imaginário é uma espécie de prática comunicacional.

Enquanto o primeiro pressuposto assinala uma avaliação do imaginário através das suas expressões comunicativas (aqui a "comunicação" é um objeto empírico de análise e podemos interrogar de que forma os media e o jornalismo contribuem para construir, consolidar ou expandir os imaginários sociais), o segundo pressuposto, por seu turno, destaca uma perspectiva comunicacional sobre o imaginário.

106 ALCEU - v. 18 - n. 36 - p. 103 a 121 - jan-jun./2018 
É precisamente esta segunda hipótese que nós privilegiamos nesta reflexão. Em contraste com uma perspectiva que investiga a área científica da comunicação como um lugar do aparecimento de constelações do imaginário, nós favorecemos uma abordagem comunicacional do imaginário que releva a imbricação das práticas comunicacionais e do princípio de publicidade na noção de imaginário social. Mais do que tema ou palco do aparecimento de imaginários sociais, a comunicação pode ser uma perspectiva. Assim, a pergunta que fazemos não é tanto o que pode a Teoria dos Imaginários trazer à Teoria da Comunicação mas exatamente a oposta: o que pode a Teoria da Comunicação oferecer ao estudo dos Imaginários Sociais. Se a Teoria da Comunicação estuda o processo pelo qual os indivíduos se relacionam entre si através de símbolos, a Teoria do Imaginário, enquanto exame ao modo como fabricamos imagens, é necessariamente parte do estudo do processo comunicacional.

Durand (1988) referia o que imaginário existe no movimento, no trajeto entre pólos e por isso refere o trajeto do sentido como algo que se aproxima mas que paradoxalmente se afasta porque o imaginário escapa a esses polos semânticos ou às definições em que o aprisionam. Pois então, é nesses trajetos (Mateus, 2014) que os imaginários se configuram comunicacionalmente: a comunicação é relação mas é sobretudo troca, interação, construção. Dentre as várias funções sociais do imaginário assinaladas por Legros et ali (2014: 12), sublinhamos a função de comunhão social na qual os imaginários contribuem para favorecer o mimetismo social, os ideais-tipo, os sistemas de representação ou a memória coletiva. Esta função social é uma função de ordem comunicacional na medida em que promove o encontro, que promove a consonância ou a identificação. Mas é igualmente uma função de ordem comunicacional, não tanto por se concentrar na dimensão mítica ou dimensão política (as ideologias revolucionárias, por exemplo) da existência social, mas por se centrar numa dimensão quotidiana, prática e prosaica da vida. As interações casuais, os encontros familiares, a posse de objeto de culto etc. são formas comunicativas pelas quais determinados imaginários se propagam. O imaginário é, assim, central na reprodução simbólica das sociedades e isso é algo que partilha inescusavelmente com a comunicação.

Assumir a comunicação enquanto ângulo de análise impele-nos, pois, a entender a matriz mediadora envolvida na natureza simbólica da acção imaginante.

Em primeiro lugar, a palavra "matriz" tem uma dupla acepção: por um lado, matriz no sentido do lugar donde se procede, lugar de gestação e amadurecimento. Por outro lado, matriz no sentido de modelo ou quadro de referência a partir do qual algo se desenvolve. A perspetiva comunicacional sugere-nos esta dupla matriz mediadora envolvida nos imaginários sociais: mediação, ela própria, fecunda e seminal, mas igualmente mediação que dá as condições necessárias ao correto desenvolvimento das estruturas significativas que habitam o imaginário.

Em segundo lugar, a mediação simbólica permite as sociedades formularem figurações concretas, tangíveis e visíveis de abstrações, conceitualizações e genera- 
lizações. Os imaginários sociais providenciam "lugares" de catarse simbólica que expurgam os equívocos. Ao oferecer imagem, ao dar mito, ao dar estrutura significativa ao inconstante, instável e efémero, a ação imaginante procede a uma mediação da vida coletiva e um núcleo de agregação em torno dos comportamentos, valores ou atitudes tidas por apropriadas.

A matriz mediadora possui, pois, a grande vantagem teórica de nos indicar o quanto os imaginários se decompõem em estratos ou matizes, e como eles são atravessados por várias ordens de ação imaginante. Por outras palavras, enfatizar a matriz seminal de mediação é apontar para a pluralidade de tipos de imaginário. Com efeito, é vulgar a sobreposição de tipos diferentes de imaginário como se eles tivessem todos o mesmo âmbito.

Assim, ao mencionarmos, numa perspetiva comunicacional, a matriz mediadora dos imaginários estamos a supor que existem, pelo menos, três tipos de imaginários: imaginários do primeiro grau correspondentes às estruturas antropológicas desde os gestos dominantes, passando pelos esquemas, arquétipos, símbolos e mitos (Durand, 1988). São imaginários predominantemente disseminados sob de forma simbolicamente mediada e frequentemente presencial (as fábulas, as histórias, lendas, mitologias, etc) mas sem envolver necessariamente meios de comunicação de massas. São imaginários profundos mas dotados de pouca amplitude (difusão relativamente restrita).

Imaginários do segundo grau onde os órgãos de comunicação de massas intervêm. São imaginários menos enraizados na vivência das sociedades, mas mais amplamente reproduzidos. Estes imaginários retomam os imaginários da primeira ordem e re-presentam-nos. Pense-se, por exemplo, na extensa iconografia do revolucionário Che Guevara que é símbolo do imaginário comunista de resistência à opressão, de reação, de liderança e da luta da minoria contra a maioria. Encontramos a efígie de Che Guevara em t-shirts, canecas, posters, capas de revista, etc.

Por fim, os imaginários do terceiro grau designam os próprios imaginários que os meios de comunicação de massas instituem a partir dos imaginários pré-existente de primeiro e de segundo grau. Referimo-nos aqui aos imaginários mediáticos (cf. Pávon, 2016; Silva, 2003) por exemplo, o imaginário da televisão, mas também ao do cinema e da forma como - retomando o exemplo anterior - re-figurou o próprio imaginário comunista, seja através de filmes ou documentários em torno da figura mítica de Che Guevara, seja através de outras formas re-configuradas da ideologia comunista.

Repare-se que, na atualidade, são os imaginários de terceira ordem com que mais nos deparamos (devido à enorme influência dos meios de comunicação) mas também são aqueles que mais intensamente são objeto de sucessivas reformulações. Tome-se o exemplo de como o cinema tem, nos últimos anos, ressuscitado as figuras épicas da mitologia grega (Hércules, Zeus, etc) e as tem re-adaptado aos novos tempos (nas ideias, nas ações empreendidas, nas representações, etc). Considere-se, também, 
o imaginário do amor romântico e o papel do romantismo nessa figuração; mas atente-se, ainda, no papel dos media, em especial do cinema da divulgação do homem e da mulher românticos. E repare-se como se evoluiu na própria definição dos agentes envolvidos (cf. Pretty Woman (1990) versus Fifty Shades of Grey (2015)). Os imaginários de terceira ordem relativos aos media tendem a ser auto-sustentáveis na medida em que correspondem a uma ecologia cognitiva cuja legitimidade e subsistência dependem precisamente da capacidade que os imaginários mediáticos possuem em se (quase autopoeiticamente) renovar. Um dos maiores exemplos contemporâneos pode ser encontrado nos reality-shows televisivos cujos participantes se tornam personagens da imprensa cor-de-rosa e imprensa televisiva. Aqui cada meio de comunicação alimenta-se do imaginário de celebridade que o outro corrobora e estimula.

Não nos alongaremos sobre estes três graus de imaginários sociais, mas queremos ressaltar que a matriz seminal de mediação é um corolário da adoção de uma perspetiva comunicacional do imaginário.

E que, dada a pluralidade de imaginários, um passo metodológico importante seria reconhecer diferentes tipos ou graus de imaginários que se digladiam em permanência pelo seu próprio reconhecimento. Nessa luta comunicativa entre graus de imaginários, os de terceiro grau, ao possuírem o domínio da reprodução simbólica associados aos media, encontram-se numa posição incrivelmente mais vantajosa e, por isso, também se explica o seu predomínio nas sociedades contemporâneas. Daí a conveniência de lidar com os imaginários mediáticos, não apenas enquanto objeto (como poderíamos estudar imaginários literários, entre tantos outros) mas sobretudo como uma expressão propriamente comunicacional dos imaginários.

Para uma integral avaliação dos imaginários sociais é, pois, recomendável tomar em consideração uma perspetiva comunicacional que possa não apenas descrever os imaginários mediáticos, mas igualmente que possa interrogar o modo como os imaginários sociais podem (re)configurar-se - ou não - como imaginários de terceiro grau.

Esta é, então, uma hipótese que decorre da matriz mediadora sublinhada na abordagem na teoria da comunicação à teoria dos imaginários sociais.

\section{Teoria da Comunicação e Imaginários Sociais}

A matéria sobre a qual operam os imaginários sociais é composta, como se afirmou, por um tecido comunicativo múltiplo e engloba não apenas mensagens dos media como histórias, gestos, hábitos e juízos com os quais uma sociedade se constrói imaginariamente. Curiosamente, umas das mais promissoras definições de "imaginários sociais" enfatiza, de algum modo, o papel do tecido comunicativo na conceção, instituição e evolução do imaginário: os imaginários sociais "são aqueles esquemas, construídos socialmente, que nos permitem perceber algo como real, 
explicá-lo e intervir operativamente no que em cada sistema social considera como realidade" (Pintos, 2000: 16). Subentendida nesta descrição está precisamente, como se intui, o papel da comunicação enquanto partilha simbólica. Este entendimento supõe que não existem realidades fora do âmbito comunicacional, pois na medida em que a realidade é construída socialmente reservamos à comunicação essa tarefa de ampliação e partilha simbólica.

O que está aqui em causa não é uma teoria da comunicação enquanto teoria do envio do sinal (cf. Modelo Matemático da Comunicação de Shannon e Weaver), mas uma teoria da comunicação enquanto aproximação ao outro, uma relação comunicativa que avança através de sucessivas seleções, cada uma contribuindo para a formação de uma compreensão comum (cf. Modelo Ritual da Comunicação de James Carey). Assim, existe uma conexão entre a Teoria da Comunicação e os Imaginários Sociais mas esta não pressupõe a atividade comunicativa como sendo linear, unidirecional ou técnica. Nenhuma tecnologia pode substituir o ser humano na construção da realidade social e na propagação dos imaginários: é certo que as tecnologias da informação expandiram a possibilidade receção da mensagem até graus inauditos. Contudo, não basta tecnologias para compreender o mundo e para produzir o património representativo das sociedades a que chamamos de imaginários sociais.

Um dos mais influentes pensadores de expressão castelhana dos imaginários, Juan-Luis Pintos (2005), também não hesita colocar a comunicação como uma operação fundamental e complexa das sociedades. É mediante a reflexão, emoção, pensamento e sentimento que a comunicação nos oferece que é possível compreender os imaginários sociais como "transcendentes comunitários" (Castoriadis, 1989: 254). A reserva de "imagens" (visuais ou não-visuais) dos imaginários dão sentido porque integram um processo comunicacional através do qual passado, presente e futuro podem ser reconhecidos. Os imaginários sociais podem, assim, ser descritos como formas de interação comunicativamente determinadas. Eles são socialmente expressivos porque encerram uma faceta comunicante, isto é, oferecem-se ativamente aos processos de intercompreensão como suporte imaginário das relações sociais. Há, como se nota, uma imbricação entre imaginários e comunicação porque a constelação de imagens mentais (o imaginário) que nos programa e, se preferirmos, molda a vida coletiva determina o modo como comunicamos. E vice-versa: o modo como comunicamos os imaginários (sejam eles de primeiro, segundo ou terceiro grau) determinam a efetividade com que influenciam a vida coletiva.

Esta relação entre comunicação e imaginários pode ser frequentemente pressuposta, porém, nem sempre é demonstrada. Com efeito, os seres humanos são "seres de comunicação" (sabemo-lo, pelo menos, desde Aristóteles). Esta é a nossa natureza: estamos biologicamente programados para nos tornarmos gregários e com isso seres sociais (o bios politikos). Mas é igualmente a nossa potencialidade porque

110 ALCEU - v. 18 - n. 36 - p. 103 a 121 - jan-jun. $/ 2018$ 
podemos recorrer à instituição imaginária para regular a nossa interação mútua. É por isso que Castoriadis (1998: 314) coloca a sociedade como auto-criativa, criação de si própria, que inaugura uma nova perspetiva sobre a ontologia. As sociedades mantêm-se unidas por intermédio das instituições significativas que fazem nascer. Mas, acrescentamos nós, é a comunicação dessas instituições que permitem que os imaginários perdurem e se assumam como verdadeiras guias de orientação.

Tome-se o exemplo: para que exista Lisboa (com todo o imaginário ligado aos elétricos amarelos, às sardinhas assadas, à calçada portuguesa ou aos bairros castiços onde se canta o Fado) é necessário que existam Lisboetas em particular. Contudo, curiosamente são os Lisboetas que são criados e que criam Lisboa. Este processo de criação e reprodução imaginária é alimentada comunicacionalmente. São os Lisboetas que reencarnam o espírito bairrista; são eles que reencenam, por exemplo, nas suas atividades económicas voltadas para o turismo os "mitos" acerca de Lisboa. São, ainda, os Lisboetas que ao adotarem os costumes e as tradições ligadas aos "Santos Populares" contribuem para fazer perdurar o imaginário Lisboeta boémio.

Os imaginários sociais não são "a realidade". Colocam-se, antes, como realidades possíveis, potenciais e construídas. Nós podemos participar numa expressão social do imaginário (ex: a Comic-Com, convenções de homenagem a personagens e heróis de banda-desenhada). Mas isso não significa que o imaginário pré-exista o ser humano. Nem sequer que possamos entrar em contacto direto com esse imaginário e que ele nos absolutamente determine enquanto seres sociais. Pelo contrário, os seres humanos criam-se a eles mesmos através dos próprios imaginários sociais (Dittus, 2006: 168). Estes não são o produto de leis objetivas, mas o resultado de múltiplas interações que a comunicação agiliza e que permite a reformulação dos imaginários de acordo com o próprio uso que as pessoas lhes dão.

O imaginário é construído socialmente, em interação contínua. E por esse motivo os imaginários sociais podem ser descritos como formas de interação comunicativamente determinadas. Sem comunicação não há sujeito consciente. Por isso, sem comunicação não existe realidade percebida. Não existem imaginários que possam ser socialmente participados. Por outras palavras, eis a comunicação como um fator central dos imaginários.

\section{O Imaginário Social necessita de Comunicação e de Publicidade}

Para aprofundarmos o papel da atividade comunicacional como aspecto fundamental dos imaginários sociais, temos de introduzir na equação um princípio societal de coparticipação e integração a que se chama de "princípio de publicidade" (Mateus, 2012).

Admitiu-se que os imaginários sociais são contribuições preciosas para a construção social da realidade, pois são dotados de uma dimensão comunicativa que 
lhes permite serem partilhados. Mas para que essa partilha atinga o máximo nível é necessário incluir o conceito de centro simbólico. E é aqui que necessitamos de referir a publicidade. A publicidade pode ser descrita como um centro simbólico que através de processos comunicacionais provoca nos imaginários sociais um elevado reconhecimento. Se a comunicação torna passível da partilha de imaginários sociais, é à publicidade que devemos a comunhão coletiva desses imaginários ao proporcionar à sociedade um núcleo simbólico. Se os imaginários sociais oferecem uma possibilidade - comunicativa - de criação da sociedade através dos patrimónios representativos e das estruturas imaginárias, aceitemos também que devemos à publicidade essa possibilidade de coparticipação num mesmo imaginário social, o mesmo é dizer, numa idêntica identidade societal.

Queremos, então, propor que o princípio de publicidade seja entendido como uma espécie de cimento coletivo que propicia a transformação da multiplicidade em unidade e da unidade em multiplicidade. É desta alquimia que vai desde o indivíduo à sua pluralidade (a sociedade) que podemos compreender o modo como os imaginários sociais não apenas são construídos socialmente como se tornam coletivamente pertinentes enquanto projetos sociais comuns. Quando declaramos a publicidade como cimento agregador pretendemos evidenciar as suas qualidades agregadoras, integradoras e simbólicas, as quais podem potencialmente regular a vida social a partir de uma orientação centrípeta. A publicidade age, pois, como força centrípeta ou convergente capaz de atrair a participação e cooperação dos indivíduos em torno de um determinado imaginário social. Ela opera como vetor concêntrico a partir do qual os imaginários sociais passam a integrar uma espécie de consciência coletiva. Note-se que os imaginários podem ser comunicados. Mas até que sejam objeto de um escrutínio público, isto é, sejam operadores publicitários, os imaginários não possuem um apelo coletivo capaz de os tornar como artefatos socialmente relevantes. A dimensão centrípeta da publicidade é o que possibilita que os imaginários adquiram força gravitacional que atraia as suas operações de instituição coletiva.

Os imaginários sociais são um fator de equilíbrio psicossocial (Dittus, 2006: 172) compensando hiatos cognitivos, contrabalançando o excessivo racionalismo e abstracionismo com as sensações e os afetos. O que agora queremos propor é que cabe à publicidade, por intermédio dessa sua força centrípeta, agregadora, convergente, de fortalecer a tendência conservadora da ordem social. Ao tornarem os imaginários coletivamente pertinentes e importantes, a publicidade opera em direção à sua permanência e reprodução. Ao se tornarem públicos, os imaginários asseguram uma estabilização social do significado fundamental para o funcionamento social. É a publicidade enquanto filtro primordial de uma realidade multidimensional e multisignificante que auxilia os imaginários a estabilizarem-se em torno, por exemplo, de certos valores. Considere-se o imaginário capitalista e a sua mobilização e cristalização em torno dos ideais do progresso, da liberdade individual, da igualdade de oportunidades, da acumulação de capital ou do laissez faire.

112 ALCEU - v. 18 - n. 36 - p. 103 a 121 - jan-jun./2018 
Pintos (2005: 47) explica que uma das mais importantes funções dos imaginários é produzir uma imagem de estabilidade das relações sociais em mudança. A construção de novos imaginários pelas gerações mais novas traduz-se na necessidade de estabelecer identidades provisórias que irão alimentar o fluxo imaginante. Nós queremos precisar que tarefa de estabilidade e continuidade das relações sociais é desenvolvida por intermédio dos imaginários mas, sugerimos deve-a à sua dimensão comunicacional pública.

A publicidade funciona como uma espécie de lente que permite identificar certas relevâncias e omitir outras dentro da formulação de um imaginário social. Não confundamos a realidade da floresta com a possibilidade de apenas vermos (com as nossas lentes especiais) uma árvore. O princípio de publicidade opera assim mesmo: filtra o que será socialmente relevante, aprimora o coletivamente reconhecido e dessa forma contribui exemplarmente para dotar os imaginários de uma imutabilidade relativa dentro do processo permanente de mutação que a dinâmica imaginária lhes imprime.

Os imaginários são, assim, mapas que através de um processo comunicativo de natureza publicitária separam aqui que é coletivamente relevante. É esta seleção que lhes confere uma potencial estabilidade simbólica que impede os imaginários sociais de explodirem numa miríade infindável de repertórios imaginantes. É à publicidade que devemos uma consolidação das práticas sociais em torno do imaginário cuja estabilidade é a necessária condição para o desenvolvimento das sociedades. Dito de forma mais rigorosa: é também à comunicação (em geral, incluindo a linguagem) e ao princípio de publicidade (em particular) que devemos uma permanência cultural capaz de assegurar a mínima institucionalidade dos imaginários.

Tal não significa que o princípio de publicidade interrompa a dinâmica imaginária. Pelo contrário, o que se defende é que a própria dinâmica dos imaginários sociais é pautada pela ação centrípeta da publicidade, a qual previne a explosão imaginante e favorece a estabilização do património representativo das sociedades. Como afirma Baeza (2011: 34): "os seres humanos necessitam de uma espécie de estabilização social do significado". Se parece indiscutível que os imaginários detêm os substratos do sentido comum, não devemos, porém, negligenciar o papel da comunicação e da publicidade na atualização das "gramáticas" que permitem articular esses substratos de sentido comum. Para que os imaginários sejam dinâmicos não basta engendrar ações imaginantes. É necessário, antes de mais, que essas ações sejam revestidas de uma dimensão comunicacional e pública de modo a que os imaginários se possam reproduzir na sabedoria (vox populi) das gerações. A força centrípeta concorre para essa estabilização dos imaginários.

O princípio de publicidade constitui, assim, o mínimo denominador comum, uma espécie de sentido comunicativo básico que garante uma interligação entre todas as tramas e mundos imaginantes (todas as suas tessituras simbólicas), todos 
os magmas de significado não apenas em relação ao passado (à memória coletiva e à história), como também em relação ao presente (a praxis social) e ao futuro (os projetos de sociedade, as utopias, o progresso).

\section{Do Imaginário Social ao Imaginal Público}

"Imaginal público" é a expressão que Mateus (2013) propõe para referir a ação comunicativa e publicitária sobre os Imaginários Sociais. O imaginal público designa a ação imaginante ocorrida por intermédio do princípio de publicidade a partir de uma perspetiva comunicacional dos imaginários sociais.

Henry Corbin (1964) foi o primeiro autor a mencionar a possibilidade de um imaginal. De acordo com a sua proposta, um imaginal denota uma imaginação meta-psicológica em que experienciamos um mundo de imagens caracterizado duplamente por uma exposição sensível a um domínio intelectual. É uma porção indizível, lugar das epifanias e do supersensível. Ao referir-se a possibilidade de um “imaginal público" estamos a afastar-nos por completo do horizonte de sentido e do âmbito filosófico de Corbin. Porém, mencionar um imaginal permite-nos recuperar a matriz generativa ou mediação imaginativa presente no pensamento do filósofo e teólogo francês. O imaginal chama-nos a atenção para a uma área cinzenta entre o mundo das sensações e perceções, e o mundo da pura intuição intelectual. No fundo, ele sublinha uma ação imaginante simbólica que precisa de se materializar, operacionalizar e tornar visível (Pintos, 2015: 153) numa matéria significante.

No contexto de uma teoria da comunicação, o imaginal assume um tipo especial de performatividade, performatividade essa particularmente aguda na publicidade. O imaginal público designa a fundamentação simbólica da atividade humana e a sua incessante figuração em torno de diferentes matérias significantes, incluindo os imaginários sociais. O imaginal público seria a expressão que salienta a dimensão comunicativa e publicitária dos imaginários e que catalisa a diversidade (essas significações magmáticas) ligando individual e coletivo, singularidade e pluralidade.

Trata-se, por outras palavras, de referir as possibilidades de variação da multiplicidade de imaginários sociais tendo em conta o efeito agregador que a publicidade lhes imprime. Deste modo, o imaginal público concerne os três graus de imaginário acima identificados, mas aponta para o trabalho de continuidade, estabilidade e centripetagem que a publicidade efetua sobre os imaginários. Conforme foi afirmado, é a publicidade que, enquanto cimento comunitário ou centro simbólico, procede a uma discriminação dos imaginários selecionando-os, relevando-os, e tornando-os coletivamente relevantes.

O imaginal público é, pois, uma ação imaginante coletiva que é atividade: isto é, age sobre os imaginários sociais tornando-os um lugar comum de encontro e confluência entre o sensível e o intelectual, entre emoção e razão, entre o pulsar 
concreto das vivências sociais e a sua remodelação multimodal em abstrações e representações coletivas (como as ideologias, por exemplo). Ele é o domínio de convergência entre imaginário e publicidade, um evento especial de ação imaginante realizada socialmente.

O conceito de imaginal público - que, insistimos, inspira-se no termo de Corbin mas que não se filia integralmente no seu pensamento - tem como grande vantagem o facto de enfatizar veementemente o quanto os imaginários se organizam de acordo com processos comunicativos (e comunitários). A expressão sublinha, assim, a eventual justaposição de diferentes e plurais imaginários sociais; mas sublinha igualmente os modos relacionais que cada imaginário pode assumir entre si no seio de processos ativos de comunicação na sociedade. Trata-se, pois, de valorizar a dimensão publicitária e coletiva dos imaginários sociais (Mateus, 2013: 43) e pode ajudar o investigador em imaginários e representações sociais a identificar e analisar os modos de influência reciproca e interpenetração dos imaginários sociais.

A ideia de imaginal público, embora perfeitamente distinta, não está muito distante de um "mundo imaginal", referido por Maffesoli (1990) como contendo todas as manifestações ou elementos do quotidiano em intensa interação. Com efeito, também o imaginal público se compõe de um universo simbólico partilhado tal como os imaginários sociais (Maffesoli, 2003) e uma valorização do presente onde despontam as emoções coletivas, a proximidade ou a socialidade. O imaginal público é, neste sentido, saturação da comunidade e uma contra-resposta à massificação unidimensional. O imaginal público é atravessado por diferentes imaginários sociais e por isso entrecruzado por diferentes movimentos de identificação social, ora distância, ora proximidade entre os indivíduos. A grande tarefa dos publicistas e das demais profissões da comunicação (jornalistas, relações públicas, advertisers etc.) é justamente mobilizar a força imaginal exercida e catalisada publicamente e colocá-la ao serviço das identidades coletivas.

A ideia de imaginal público alberga o fluxo imaginante com vista a traçar as rotas e os trajetos dos imaginários nos seus muitos processos de diferenciação e consolidação. Contudo, a sua maior potencialidade é acolher a possibilidade da imaginação individual e imaginação coletiva, ambas poderem afetar-se duplamente no seio de sociedade através de uma ampla afirmação pública. O imaginal público é, a esta luz, uma estrutura desestruturada onde se ensaiam coletivamente diversos "imaginares". E por isso a ideia de um imaginal público é consistente com uma panóplia de imaginários que permeiam as sociedades lutando pelo reconhecimento público, lutando para se tornarem predominantes, lutando para se expandirem pelo nível máximo de magma de significados.

$\mathrm{Na}$ medida em que os múltiplos imaginários sociais continuarem a circular na sociedade, na medida em que persistirem em se afirmar comunicacionalmente, qualquer imaginário é um potencial imaginário a integrar o imaginal público. As 
sucessivas disposições imaginantes são tentativas de construir relações sociais. Essas relações sociais poderão transformar-se num contexto público passando a integrar o imaginal público, essa síntese de "imaginares" coletivamente relevantes.

Em resumo, tendo em conta uma teoria da comunicação, propomos que se fale em "imaginal público" como um fundo de conjuntos complexos de imaginários sociais inter-relacionados que são publicamente disseminados. O imaginal público reside fora do pensamento objetivo ou concreto. É êxtase e arrebatamento dos sucessivos entrecruzares de imaginários que se derramam na mediação comunicativa. Ele é lugar de convocação, formulação e refiguração imaginante, espaço onde as trajetórias dos sucessivos imaginares se desenvolvem. É nesse espaço que os símbolos se atualizam e os imaginários se movem socialmente.

Essa disseminação pública contida no conceito não corresponde estritamente à mediatização nem a imaginários de terceiro grau. A disseminação aponta, neste contexto, para a propagação publicitária que alguns imaginários sociais atingem e que lhes permitem sobrepor-se a imaginários congéneres. Por exemplo, o imaginário do amor romântico (com os arquétipos da dama e do vagabundo, só para ilustrar) é claramente predominante no cinema norte-americano contemporâneo face ao amor conjugal ou o amor maternal. Essa disseminação por entre o tecido publicitário das sociedades permite-nos uma maior difusão de comportamentos concordantes e uma maior afirmação coletiva.

Com efeito, é disso mesmo que se trata ao sugerirmos a noção de "imaginal público": a referenciação matricial, generativa e desmultiplicadora das relações simbólicas que diferentes imaginários estabelecem entre si e entre si e as sociedades. E como a sua realização não pode ser afastado da sua integração em processos comunicacionais e publicitários.

\section{Conclusão}

Sublinhar um imaginal público corresponde a inverter o papel da comunicação em relação aos imaginários sociais. Isto é, não tanto questionar a dimensão imaginante da comunicação, mas interrogar a dimensão comunicacional dos imaginários sociais.

Uma teoria da comunicação preocupada, não com a transmissão unidirecional da informação através de um medium mas centrada sobre a lógica pragmática, performativa e imprevisível de agentes sociais em interação reciproca, tem muito a oferecer à teoria dos imaginários sociais. Como tal, ao discriminar o modo como a estabilização e a continuidade dos imaginários sociais ocorre por intermédio do princípio de publicidade estamos um passo mais perto de formular uma teoria da comunicação capaz de assumir uma dimensão crítica. Mas igualmente capaz de assumir o fenómeno comunicacional enquanto experiência e enquanto vivência de acordo com uma tradição fenomenológica que descreve os encontros entre indivíduos como uma negociação 
entre mundos heterogêneos. Ao prevenir uma informacionalização universal das técnicas de comunicação, a teoria da comunicação é um campo fundamental para dar conta de como os imaginários sociais trabalham os seus patrimónios representativos e os seus reservatórios significantes.

Este artigo propôs um ponto de vista sobre um potencial contributo que a teoria da comunicação pode oferecer à teoria dos imaginários sociais, debatendo a ambiguidade que uma perspetiva comunicacional encerra. De fato, podemos utilizar a comunicação como objeto de exploração de imaginários. Mas podemos, também, apropriar-nos da comunicação como ângulo de análise capaz de mobilizar a teoria da comunicação ao serviço da teoria dos imaginários sociais. Foi a partir precisamente desta premissa que se postulou a possibilidade dos imaginários sociais se assumirem como formas de interação simbólica (em sentido lato) comunicativamente determinadas.

Daqui decorre a importância (e a justificabilidade) da noção de "imaginal público". Esta expressão possui como grande vantagem enfatizar a dimensão comunicativa dos imaginários mas igualmente a sua dinâmica imaginante e as suas incessantes interações com outros imaginários sociais na arena publicitária. Mais, o imaginal público salienta a justaposição complexa de múltiplos e diversos imaginários nas sociedades o que significa valorizar a dimensão agonística, interativa e participativa dos imaginários sociais.

Por fim, devemos assinalar que o imaginal público denota a confluência de imaginários. Nessa medida, ele reflete as disposições imaginantes, os patrimónios simbólicos ou os magmas de significados que afloram nos imaginários. Por isso, o imaginal público é, em certa medida, a expressão comunicativa da "potência imaginária" (Morin, 1995: 40), uma irradiação impetuosa de imagens mentais e materiais que ampliam ou reduzem a realidade que dão a percepcionar.

Enquanto potência imaginária, o imaginal público caracteriza-se por ser um desdobramento e uma projeção da realidade cujo atributo maior é permitir às potências imaginantes se fixarem coletivamente por intermédio de um ativo processo publicitário. O imaginal público seria, assim, um campo de proliferação das imagens (num sentido amplo que inclui os conceitos enquanto imagens mentais). Todavia, não se trata de uma proliferação desmedida e irremediável, mas uma multiplicação e generalização que é paradoxalmente uma cristalização das necessidades e desejos humanos. Deste modo, o imaginal público assume a função de facilitador da imagem ao consagrar-se como campo onde a imaginação se torna imaginário e o imaginário, na sua potência do múltiplo, se torna comungado, partilhado e coletivo.

Em suma, a aproximação entre a teoria da comunicação e a teoria dos imaginários sociais que o conceito de "imaginal público" propicia possui vantagens para cada um dos domínios de pensamento: do ponto de vista da comunicação, significa uma 
radicalização imaginante da publicidade; do ponto de vista dos imaginários sociais, significa uma radicalização comunicante das imagens. Daí ressalta uma ostensiva porosidade entre a comunicação e o imaginário de que o imaginal público poderá ser a mais óbvia constatação.

Samuel Mateus

Professor da Universidade da Madeira Doutor em Ciências da Comunicação, Universidade Nova de Lisboa samuelmateus@uma.pt

Recebido em setembro de 2017.

Aprovado em março de 2018.

\section{Notas}

1 Observamos como instituições imaginárias fundamentam todos os tipos de sociedade, deste as sociedades não-literárias até às sociedades pós-modernas. Seja enquanto Mito (Antropologia Estruturalista), seja quanto Simulação ou Imagemcópia (o Hiper-Real de Baudrillard, por exemplo), verificamos a persistência de estruturas imaginantes na ordenação da ação social. A própria antropologia do imaginário (Eliade, Bachelard, Durand) que coloca o imaginário como produto de um pensamento mítico contesta a ideia de que esse pensamento seria primitivo, pré-lógico ou inferior ao pensamento racional.

2 A ideia de Esfera Pública desenvolveu-se com Habermas a partir do sentido etimológico de Öffentilichkeit, sendo a publicidade associada sobretudo à noção de Esfera Pública e ao anúncio comercial de mensagens. Apelando à etimologia de publicidade (enquanto qualidade pública), usamos a palavra para além da conformação crítico-racional ou normativa (Cf. Mateus, 2012).

3 Este pressuposto é evidente na noção de "trajectórias do sentido" proposta por Durand (1988) e em "trajectórias do imaginário" elaborada por Mateus (2014).

4 Um exemplo seria Benassimi (2002) onde a autora estuda empiricamente o imaginário dos profissionais da comunicação.

5 O imaginário da femme fatale existe desde o século XX mas está hoje complemente remodelado face ao seu congénere dos anos 1920. E para isso contribui a renovação que o cinema lhe emprestou mas também os novos estilos de vida da mulher contemporânea)

6 Neste ponto afastamo-nos da proposta de Durand (1988) porque para este autor o "símbolo" é entendido sobretudo como palavra e manifestação cultural do arquétipo. Além disso, deve ser sublinhado que a hipótese de um imaginal público supõe um nível de teorização que não se confunde com a noção de "imaginal" com que Durand trabalha. É verdade que retém a ideia de Durand de que o imaginal ordena as actividades do consciente, e que opera de forma arquetípica. Porém, a 
faceta do imaginal como acesso ou convocação do Ser, espécie de gnose, encontrase ausente na perspectiva de um "imaginal público" enquanto referenciação das relações simbólicas que diferentes imaginários estabelecem entre si e entre si e as sociedades. Assim, a presente reflexão não se insere estritamente na tradição de Corbin ou Durand. A eventualmente pertinente - e instigante - discussão das consonâncias e dissonâncias de "imaginal" e "imaginal público" não cabe, todavia, nesta reflexão, a qual se dedica a procurar enfatizar uma perspectiva comunicacional dos imaginários.

\section{Referências}

BACZKO, Bronislaw. Los imaginarios sociales. Memorias y esperanzas colectivas. Buenos Aires: Editorial Nueva Visión, 1991.

BAEZA, Manuel Antonio. Los caminos invisibles de la realidad social. Ensayo de sociología profunda sobre los imaginarios sociales. Santiago de Chile: RiL, 2000

Elementos básicos de una teoría fenomenológica de los imaginarios sociales. In: COCA, Juan R.; VALERO, Jesús; RANDAZZO, Francesca; PINTOS, Juan Luis (Coord.). Nuevas posibilidades de los imaginarios sociales. Badajoz: TREMN-CEASGA, 2011, pp. 31-42.

BARROS, Ana Taís Martins Portanova. O imaginário e a hipostasia da comunicação. Comunicação, mídia e consumo - revista do Programa de Pós-Graduação em Comunicação e Práticas de Consumo ESPM, São Paulo, ano 10, v. 10, n. 29, 2013, pp. 13-29.

BENASSIMI, Claudia. El imaginario social del comunicador: una propuesta de acercamiento teórico. Razón y palabra, n. 25, 2002.

CABRERA, Daniel H. Imaginario social, comunicación e identidad colectiva. In: Comunicación y diversidad cultural. Forum Barcelona. Institut de la Comunicació-Universitat Autònoma de Barcelona, 2004.

CASTORIADIS, Cornelius. La institución imaginaria de la sociedad. El imaginario social y la institución. Barcelona: Tusquets Editores, 1989.

. Hecho y Por Hacer. Pensar la imaginación. Buenos Aires: Editorial Universitária

de Buenos Aires, 1998.

CORBIN, Henry. Mundus Imaginalis or the Imaginary and the Imaginal 1964 acedido em Junho de 2016 em http://www.hermetic.com/bey/mundus_imaginalis.htm.

DITTUS, Rúben. El Imaginario Social y su aporte a la teoría de la comunicación: seis argumentos para debatir. In: Cinta Moebio, 26, 2006, pp. 166-176

DURAND, Gilbert. A imaginação simbólica. São Paulo: Cultrix, 1988.

DURKHEIM, Émile. The Elementary Forms of Religious Life, Oxford: Oxford University Press, 2001.

LEGROS P, et ali. Sociologia do Imaginário, Porto Alegre. Editora Sulina, 2014.

MAFFESOLI, Michel. Au creux des apparences, Paris, Plon, 1990.

"El imaginario social." Revista Anthropos, 198, 2003, pp. 149-153.

MATEUS, Samuel. O Principio de Publicidade - da dimensão crítica à dimensão socio-antropológica. In: Cadernos de Estudos Mediáticos, n.9, 2012 pp.71-83.

O Arquétipo Publicitário. In: Revista Famecos 19, 3, 2012a, pp. 630 - 643.

O Imaginal Público: prolegómenos a uma abordagem comunicacional do

imaginário. In: Revista Comunicação, Mídia e Consumo, v.10, n.29, 2013, pp.31-50. 
. "Some Vectors on the Imaginal Trajectory" In Klein, Araújo, Contrera (org.), Theories of the Image and the Imaginary, Compós, 2014, pp. 320-338, ISBN: 978-85-68803-00-4 MORIN, Edgar, Le cinéma ou l'homme imaginaire: Essai d'anthropologie sociologique. París: Les Editions de Minuit, 1995.

PASÍN, Angel Carretero. "Imaginario e identidades Sociales: los escenarios de actuación del imaginario social como configurador de vínculo comunitário” IN Coca, Matas, Randazzo y Pintos (coord.). Nuevas posibilidades de los imaginarios sociales, Editorial CEASGA-Edición TREMN, 2011, pp. 99-112.

PÁVON, Ignacio Riffo. "Una Reflexion para la Comprensión de los Imaginarios Sociales”, Comuni@accion, vol.7,no1,2016,pp.63-76.

PINTOS, Juan-Luis. Los imaginarios sociales: la nueva construcción de la realidad social. Cantabria: Editorial Sal Terrae, 1995.

. "Construyendo realidad(es): Los imaginarios sociales". Revista Realidad (U. A. J. F. Kennedy), no 1, pp. 7-25, 2000.

“Comunicación, construcción de la realidad e imaginarios sociales". Utopía y Praxis Latinoamericana, año 10, no. 29, abril-junio, 2005, pp. 37-65.

. "Apreciaciones sobre el concepto de imaginarios sociales". Revista de Investigación Miradas. Vol. 1, No 13, 2015, pp. 150-159

SAEZ, Felipe Aliaga, PASIN, Enrique Carretero. "El abordaje sociológico de los imaginarios sociales en los últimos veinte anõs”. Espacio Aberto- caderno venezuelano de sociología, Vol.25. n.4, 2016, pp.117-128.

SILVA, Juremir Machado da. Tecnologias do imaginário. Porto Alegre: Sulina, 2003.

SOLA-MORALES, Salomé. "Imaginarios Sociales, procesos de identificación y comunicación mediática”. Prisma.com, vo.25, 2014, pp. 3-22.

WUNENBURGER, Jean-Jacques. Antropología del imaginario. Buenos Aires: Ediciones del Sol, 2008. 


\title{
Resumo
}

O presente artigo analisa as potenciais contribuições que a teoria da comunicação pode oferecer à teoria dos imaginários sociais a partir de um debate acerca da ambiguidade que uma perspetiva comunicacional encerra. Com efeito, podemos utilizar a comunicação como objeto empírico de estudo dos imaginários. Mas podemos, igualmente, apropriar-nos da comunicação como ângulo de análise capaz de mobilizar um trabalho comunicacional em torno dos imaginários sociais.

Adotando esta segunda hipótese, releva-se a possibilidade dos imaginários sociais se assumirem como formas de interação simbólica (em sentido lato) comunicativamente determinadas. Com efeito, é defendido que a ação imaginante denota uma ordem comunicacional. Reconhecer esta dimensão comunicacional dos imaginários sociais envolve ponderar o papel da publicidade na figuração e re-figuração dos imaginários sociais e por isso propomos a noção de "imaginal público" enquanto fluxo imaginante, como um campo de proliferação de imagens e símbolos onde podemos observar as rotas e os trajetos dos imaginários sociais nos seus muitos processos de diferenciação e consolidação.

\section{Palavras-chave}

Imaginário Social. Teoria da Comunicação. Imaginal. Princípio de Publicidade.

\begin{abstract}
This paper examines the potential contributions that communication theory can offer to social imaginaries theory stemming from the ambiguity which a communicational perspective encloses. In fact, we can use communication as empirical study of the imaginary object. But we can also see communication as an angle of analysis capable of mobilizing a communicational perspective on the social imaginary.

From this second standpoint, there is the possibility of social imaginaries to assume communicatively determined forms of symbolic interaction (in a broad sense). Indeed, it is argued that imaginative activity denotes a communicational dimension. To recognize this communicative dimension of social imaginaries involves considering the role of publicity in figuration and re-figuration of the social imaginary; and so we advance the notion of "public imaginal" as imaginative flux, as a field of imagistic and symbolic proliferation in which we can observe the routes and paths of social imaginaries in their many processes of differentiation and consolidation.
\end{abstract}

\section{Keywords}

Social Imaginary. Communication Theory. Imaginal. Publicity Principle. 